\title{
Hereditary Thrombophilia Risk Factors In Patients With
}

\section{Venous Thromboembolism}

\author{
Sabahattin Destek ${ }^{1}$, Vahit Onur Gül ${ }^{2^{*}}$ \\ ${ }^{1}$ Bezmialem Vakif University School of Medicine, Department of General Surgery, Istanbul, Turkey \\ ${ }^{2}$ Gulhane Education and Research Hospital Department of General Surgery Ankara, Turkey
}

\begin{abstract}
Venous thromboembolic disease (VTD) is a serious cause of mortality and morbidity with an incidence of $0.1 \%$ per year. The etiology of VTD is multifactorial and associated with acquired and hereditary conditions. The aim of our study was to investigate the presence of rare genetic mutations in VTD patients and to evaluate their distribution according to thrombosis sites.

The study group consisted of 107 patients who underwent genetic testing for thrombophilia due to VTD between 2015 and 2017. Patients with VTD who underwent thrombophilic genetic examination by polymerase chain reaction method were included in the study. Antithrombin III, protein C and protein S deficiency patients diagnosed with biochemical tests were excluded from the study. The demographic characteristics and clinical results of the patients were obtained from the hospital archive. The control group consisted of 112 healthy individuals randomly selected from the community. The patient group and the control group were compared.

The mean age of the patients was 39.6 years. The female/male ratio was 1.7. Advanced age and female gender were statistically significantly more frequent in the patient group (In both, $\mathrm{p}=0.0001$ ). Factor V G1691A and B-Fibrinogen-455 genetic defects were statistically significantly higher in the patient group (Respectively; $\mathrm{p}=0.008, \mathrm{p}=0.049$ ). The most frequent $(54.2 \%)$ PAI-4G\&5G heterozygous gene defect was found in the patients. Deep venous thrombosis was detected in $54.2 \%$, intraabdominal VTD in $4.7 \%$, pulmonary embolism in $27.1 \%$, and cerebral venous thrombosis in $30.8 \%$ of the VTD patients.

Thrombophilic genetic mutations are not uncommon in patients with VTD. Thrombophilic genetic mutations in VTD etiology and in selected patients should be investigated. In patients without known thrombophilia mutations, rare thrombophilic mutations should be examined.
\end{abstract}

Key Words: Venous thromboembolic disease, hereditary thrombophilia, rare thrombophilic mutations

\section{Introduction}

Venous thromboembolic disease (VTD) is the formation of venous occlusion due to pathologic thrombus development in veins. According to the theory described for the first time by Rudolph Virchow in 1856, stasis, venous wall damage and local hypercoagulability in blood are the three main causes in the VTD etiology (1).

The annual incidence of VTD is $0.001 \%$ in children and $0.1 \%$ in adults $(1,2)$. The incidence increases with age, reaching $1 \%$ over the age of 85 years $(1,2)$. Of the VTD patients, two thirds have lower limb deep vein thrombosis (DVT) and one third have pulmonary embolism (PE) (2). The major complications of VTD are post-thrombotic syndrome, major bleeding due to anticoagulation, recurrence and death $(1,2)$.

Even though VTD can be due to inherited or acquired causes, multiple causes are concomitantly present in many of the patients. Today it is estimated that the susceptibility to thrombosis in more than $60 \%$ of the cases is linked to the genetic components (2-4).

Factor $\mathrm{V}$ Leiden is the most common and wellstudied genetic cause of VTE, followed by the prothrombin G20210A gene mutation and deficiencies in protein $\mathrm{S}$, protein $\mathrm{C}$, and antithrombin $(2,4)$. Some other mutations and polymorphisms have also been proposed as genetically determined procoagulant risk factors for VTE (3-5).

Hereditary defects that cause VTD continue to be studied. In this study, we focused on rare genetic mutations, which are reported to be the cause of VTD. Rare genetic mutations in patients and their relationship with the presence of VTD in various localizations were examined. Thus, the role and importance of rare genetic mutations in VTD etiology was examined. 


\section{Materials and Methods}

Study Group: Between 2015 and 2017, patients with VTD who underwent genetic examination for thrombophilia in our hospital were examined for hereditary thrombophilic disorders and compared with the healthy control group. For the study, 15/216 numbered and 15/08/2017 dated Ethics Committee approval was obtained from Bezmialem Vakif University. Our study received written approval from all individuals.

In our hospital, the diagnosis of antithrombin III, protein $\mathrm{C}$ and protein $\mathrm{S}$ deficiency was usually determined by biochemical tests. Patients with 164 VTD who were biochemically determined to have antithrombin III, protein $\mathrm{C}$ and protein $\mathrm{S}$ deficiency and were not genetically tested were excluded from the study. Forty-four patients with genetically determined antithrombin III, protein C and protein $\mathrm{S}$ deficiency were excluded from the study for homogenization of the study. Patients with arterial thrombus, retinal vein thrombus, thoracic outlet syndrome and catheter-related upper extremity thrombus were excluded.

A total of 107 VTD patients with the following genetic tests were included in the study: Factor $\mathrm{V}$ mutation analyses (G1691A-Leiden and H1299RFVR2), Factor II prothrombin (G20210A), Methylenetetrahydrofolate reductase (MTHFR) mutation analyses (C677T and A1298C), Factor XIII (V34L), Beta-fibrinogen (-455 G-A), Plasminogen activator inhibitor 1 (PAI-1) $(4 \mathrm{G} / 5 \mathrm{G})$, Angiotensin converting enzyme (ACE) (I/D), Human platelet antigen-1 (Glycoprotein IIIa-GPIIIa) (HPA-1) (a/b), Apolipoprotein B (ApoB, R3500Q) (ApoB-100), Apolipoprotein E (ApoE) (e2, e3 and e3 alleles). ${ }^{4}$ Heterozygous and homozygous mutations in thrombophilic gene mutations were evaluated in all subjects. In this respect, both groups were compared.

The control group consisted of 112 people. The control group was randomly selected healthy individuals. There was no consanguinity between the control group and the individuals in the patient group. Thrombophilic genetic tests performed in the study group were also performed in the control group. The genetic mutations of the patients with VTD were compared with those of the control group. Demographic characteristics of patients in the study group, thrombosis regions and thrombophilic genetic mutations in these areas were examined.

Study Investigations: It was found that physical examination, D-dimer measurement, VTD imaging methods such as doppler ultrasonography (DS), venography, computed tomography (CT), magnetic resonance imaging (MR), ventilationperfusion scintigraphy and angiography were used in these patients $(1,4)$.

While determining the gene mutations of the individuals undergone genetic test for thrombophilia, venous blood sample was taken into a tube with ethylenediaminetetraacetic acid (EDTA) and DNA isolations were made from the peripheral blood leukocytes in $200 \mu$ l of peripheral blood samples for two weeks using High Pure PCR Template Preparation Kit. Then, the gene sequences of thrombophilic mutations were reproduced in vitro from the isolated DNAs with the multiplex PCR method and in vitro amplification was carried out using double primers with the PCR multiplex method on the gene chains to probe defects utilizing a mutation detection kit. After hybridization, the mutations in the thrombophilic genes were examined in the LightCycler device and the presence of homozygous and heterozygous genotype was identified with the Melting Curve program.

Statistical Analysis: The data obtained in this study were analyzed with the licensed SPSS 21 package program. Descriptive statistical data, mean and standard deviation of continuous variables were shown. Categorical variables were represented by frequency and percentage. The Chi-square $(\chi 2)$ analysis was carried out in analysis of the differences of nominal variables between the groups. In cases where the expected values in the cells of the tables did not have sufficient volume, the Fisher's Exact Test pr the Pearson Chi-square analysis using Monte Carlo simulation was performed depending on the suitability of the data. While interpreting the results, a significance level of 0.05 was used; it was indicated that there is a significant difference in the case of $p<0,05$, whereas there was not a significant difference in the case of $\mathrm{p}>0.05$.

\section{Results}

The mean age was 31.7 in the control group and the Female/Male ratio was 10.2. The mean age was 39.6 years in the VTD patient group, and the Female/Male ratio was 1.7. The age of the patient group was statistically significantly higher than the control group $(\mathrm{p}=0.0001)$. The female ratio was $63.6 \%$ in the patient group and $91.1 \%$ in the control group; there was a statistically significant difference between the groups $(p=0.0001)$. (Table 1). 
Table 1. The demographic and clinical characteristics of the patient and control groups

\begin{tabular}{lccc}
\hline \multirow{2}{*}{ Parameters } & $\begin{array}{c}\text { Patient Group } \\
(\mathrm{n}: 107) \mathrm{n}(\%)\end{array}$ & $\begin{array}{c}\text { Control Group } \\
(\mathrm{n}: 112) \mathrm{n}(\%)\end{array}$ & Test \\
\hline Age (year), (mean) & $2-75(39.6)$ & $2-59(31.8)$ & $0.0001 ¥$ \\
Female/Male & 1.7 & 10.2 & $0.0001^{\Phi}$ \\
Heterozygous Defect, (mean) & $0-8(3.6)$ & $1-8(2.9)$ & $0.0001 ¥$ \\
Homozygous Defect, (mean) & $0-4(1.2)$ & $0-3(1)$ & $0.204 ¥$ \\
Common gene defect: ACE I/D, n (\%) & $88,(82.2 \%)$ & $83(74.1 \%)$ & $0.197 \Phi$ \\
Rare Genetic Mutations: & $26,(24.3 \%)$ & $12,(10.7 \%)$ & $0.008^{\Phi}$ \\
B-Fibrinogen-455, n (\%) & $62,(57.9 \%)$ & $49,(43.8 \%)$ & $0.049^{\Phi}$ \\
Factor V G1691A, n (\%) & & & \\
\hline
\end{tabular}

$¥:$ The independent t-test

$\phi$ : Chi-square analysis

Of the 436 thrombophilic gene defects identified in the control group, $73.6 \%$ were heterozygous, $26.4 \%$ were homozygous defects. Of the 511 thrombophilic gene defects identified in the patient group, $75.1 \%$ were heterozygous and $24.8 \%$ were homozygous disorders. The number of heterozygous defects was significantly higher in the patient group and there was a statistically significant difference between the groups $(\mathrm{p}=0.0001)($ Table 1$)$.

Proportionally, the most common thrombophilic gene defect was ACE I/D gene defect with $82.2 \%$ in the patient group and ACE I/D gene defect with $74.1 \%$ in the control group. Statistically, the rate of Factor V G1691A mutation was $24.3 \%$ in the patient group, and $10.7 \%$ in the control group; there was a statistically significant difference between the groups $(p=0.008)$. Again, the rate of patients with B-Fibrinogen-455 gene mutation was $57.9 \%$ in the patient group, and $43.8 \%$ in the control group; there was a statistically significant difference between the groups $(p=0.049)$. According to heterozygous/homozygous differentiation, Factor V G1691A heterozygous disorder was statistically significantly higher in the patient group ( $\mathrm{p}=0.008)$ (Table 2).

In our study, $68 \%$ of ACE gene mutations were found in women in the patient group and statistically significant $(\mathrm{p}=0.032)$. In the control group, $75 \%$ of Factor V G1691A gene mutations were found in women and were statistically significant $(\mathrm{p}=0.039)$.

In the patient group, DVT was found as $54.2 \%$, intraabdominal VTD (IAVTD) as $4.7 \%$, PE as $27.1 \%$ and cerebral vein thrombosis (CVT) as $30.8 \%$. In our study, Factor V G1691A (n:20, \%76.9) and MTHFRA 1298C (n:39, \%62.9) thrombophilic gene defects were statistically significantly higher in the DVT patients
(Respectively; $\mathrm{p}=0.008, \mathrm{p}=0.034)$. Factor V G1691A (n:22, 29.7\%) thrombophilic gene defects were statistically significantly higher in the CVT patients $(p=0.049)$. Statistically, DVT was significantly more common in females $(p=0.004)$ while CVT was significantly less common in females $(\mathrm{p}=0.009)($ Table 2-3).

\section{Discussion}

Venous thrombosis and associated complications are the most common emergency vascular disease after acute ischemic heart disease and stroke (5). The annual incidence of VTD is 104-183 per $100,000(2.3)$. The annual incidence of VTD increases with age, reaching $1 \%$ over 85 years of age $(6,7)$. The $\mathrm{F} / \mathrm{M}$ ratio has been reported as 1.2 in the literature, while it was found to be 1.7 in our patient group $(5,7)$. In our study, VTD was more common in women.

The etiological factors of VTD are defined as hereditary and acquired $(8,9)$. According to frequency order, the major hereditary causes are active factor $\mathrm{V}$ Leiden mutation, prothrombin G20210A mutation, etc $(10,11)$. The major acquired causes include major surgery, active cancer, immobilization, inpatient treatment, trauma, pregnancy, oral contraceptive use, etc (1217). In thrombophilic gene tests that we performed for VTD and hereditary causes, Factor V G1691A and B-Fibrinogen-455 gene mutations were statistically significantly higher in the patient group. The ACE gene mutation was statistically significantly higher in females in the patient group.

The most common venous thromboembolic disease is DVT. Without PE, the annual incidence of DVT is $45-117$ per 100,000 people and the incidence of PE is 29-78 per 100,000 people 
Table 2. Thrombophilic mutation types according to the groups

\begin{tabular}{|c|c|c|c|c|c|c|c|c|c|}
\hline \multirow{3}{*}{ Thrombophilic Gene } & \multirow{3}{*}{$\begin{array}{l}\text { Mutation } \\
\text { Presence }\end{array}$} & \multicolumn{6}{|c|}{ Groups } & \multirow{2}{*}{\multicolumn{2}{|c|}{ Test }} \\
\hline & & \multicolumn{2}{|c|}{ Patient } & \multicolumn{2}{|c|}{ Control } & \multicolumn{2}{|c|}{ Total } & & \\
\hline & & $\mathrm{n}$ & $\%$ & $\mathrm{n}$ & $\%$ & $\mathrm{n}$ & $\%$ & Value & $\mathrm{p}^{\phi}$ \\
\hline \multirow{2}{*}{ Factor V G1691A } & Normal & 81 & 75,7 & 100 & 89,3 & 181 & 82,6 & \multirow{2}{*}{7,042} & \multirow{2}{*}{0,008} \\
\hline & Mutational & 26 & 24,3 & 12 & 10,7 & 38 & 17,4 & & \\
\hline \multirow{2}{*}{ Mutation Types } & Heterozygous & 23 & 21,5 & 12 & 10,7 & 35 & 16,0 & \multirow{2}{*}{9,559} & \multirow{2}{*}{0,008} \\
\hline & Homozygous & 3 & 2,8 & 0 & 0,0 & 3 & 1,4 & & \\
\hline \multirow{2}{*}{ Factor V H1299R } & Normal & 81 & 75,7 & 83 & 74,1 & 164 & 74,9 & \multirow{2}{*}{0,074} & \multirow{2}{*}{0,789} \\
\hline & Mutational & 26 & 24,3 & 29 & 25,9 & 55 & 25,1 & & \\
\hline \multirow{2}{*}{ Mutation Types } & Heterozygous & 24 & 22,4 & 28 & 25,0 & 52 & 23,7 & \multirow{2}{*}{0,558} & \multirow{2}{*}{0,757} \\
\hline & Homozygous & 2 & 1,9 & 1 & ,9 & 3 & 1,4 & & \\
\hline \multirow{2}{*}{ Factor II G20210A } & Normal & 99 & 92,5 & 108 & 96,4 & 207 & 94,5 & 1611 & \\
\hline & Mutational & 8 & 7,5 & 4 & 3,6 & 12 & 5,5 & 1,011 & 0,204 \\
\hline Mutation Tunes & Heterozygous & 7 & 6,5 & 4 & 3,6 & 11 & 5,0 & 2492 & 02 \\
\hline Mutation 1 ypes & Homozygous & 1 & 0,9 & 0 & 0,0 & 1 & 0,5 & 2,492 & 0,288 \\
\hline & Normal & 46 & 43,0 & 58 & 51,8 & 104 & 47,5 & 1607 & 0103 \\
\hline MTHFR C & Mutational & 61 & 57,0 & 54 & 48,2 & 115 & 52,5 & 1,091 & 0,193 \\
\hline Mut & Heterozygous & 50 & 46,7 & 41 & 36,6 & 91 & 41,6 & 2328 & $033-3$ \\
\hline Mutation 1 ypes & Homozygous & 11 & 10,3 & 13 & 11,6 & 24 & 11,0 & $2,3<8$ & 0,312 \\
\hline MTHFR A & Normal & 45 & 42,1 & 56 & 50,0 & 101 & 46,1 & 130 & \\
\hline МIHFК AIZ98С & Mutational & 62 & 57,9 & 56 & 50,0 & 118 & 53,9 & 1,39 & 0,238 \\
\hline & Heterozygous & 47 & 43,9 & 45 & 40,2 & 92 & 42,0 & & \\
\hline Mutation Types & Homozygous & 15 & 14,0 & 11 & 9,8 & 26 & 11,9 & 1,744 & 0,4 \\
\hline Factor XII & Normal & 74 & 69,2 & 90 & 80,4 & 164 & 74,9 & 3649 & 00 \\
\hline Factor Xi11 V $34 \mathrm{~L}$ & Mutational & 33 & 30,8 & 22 & 19,6 & 55 & 25,1 & 3,049 & 0,050 \\
\hline Mutation Tynes & Heterozygous & 31 & 29,0 & 19 & 17,0 & 50 & 22,8 & 4559 & 0102 \\
\hline Mutation 1ypes & Homozygous & 2 & 1,9 & 3 & 2,7 & 5 & 2,3 & 4,559 & 0,102 \\
\hline & Normal & 45 & 42,1 & 63 & 56,3 & 108 & 49,3 & & \\
\hline B-Fibrinogen-45b & Mutational & 62 & 57,9 & 49 & 43,8 & 111 & 50,7 & 3,861 & 0,049 \\
\hline & Heterozygous & 51 & 47,7 & 43 & 38,4 & 94 & 42,9 & 5.04 & 00 \\
\hline Mutation 1уре & Homozygous & 11 & 10,3 & 6 & 5,4 & 17 & 7,8 & 3,04 & 8 \\
\hline I-1 $4 G \delta$ & Normal & 28 & 26,2 & 33 & 29,5 & 61 & 27,9 & 0155 & $060^{-1}$ \\
\hline PA1-1 4G\&5G & Mutational & 79 & 73,8 & 79 & 70,5 & 158 & 72,1 & 0,153 & 0,094 \\
\hline Mutat & Heterozygous & 58 & 54,2 & 57 & 50,9 & 115 & 52,5 & 0328 & 0849 \\
\hline Mutation 1 ypes & Homozygous & 21 & 19,6 & 22 & 19,6 & 43 & 19,6 & & \\
\hline tion & Normal & 19 & 17,8 & 29 & 25,9 & 48 & 21,9 & 1668 & 01 \\
\hline ACE Gene mutation & Mutational & 88 & 82,2 & 83 & 74,1 & 171 & 78,1 & 1,008 & 0,191 \\
\hline Mutation Tunes & Heterozygous & 46 & 43,0 & 41 & 36,6 & 87 & 39,7 & 2258 & 03 \\
\hline Mutation Iypes & Homozygous & 42 & 39,3 & 42 & 37,5 & 84 & 38,4 & 2,258 & 0,320 \\
\hline HPA-1 & Normal & 74 & 69,2 & 87 & 77,7 & 161 & 73,5 & 1626 & 0202 \\
\hline & Mutational & 33 & 30,8 & 25 & 22,3 & 58 & 26,5 & $1,0<0$ & \\
\hline & Heterozygous & 30 & 28,0 & 21 & 18,8 & 51 & 23,3 & & \\
\hline Mutation 1ypes & Homozygous & 3 & 2,8 & 4 & 3,6 & 7 & 3,2 & $2,0 / 1$ & 0,202 \\
\hline$A \cap B R$ & Normal & 107 & 100,0 & 112 & 100,0 & 219 & 100,0 & & \\
\hline Аров Кз500 Q & Mutational & 0 & 0,0 & 0 & 0,0 & 0 & 0,0 & - & - \\
\hline AnoF Genotvne & Normal & 74 & 69,2 & 89 & 79,5 & 163 & 74,4 & 3054 & 0081 \\
\hline Aрое Genotype & Mutational & 33 & 30,8 & 23 & 20,5 & 56 & 25,6 & 3,034 &, 001 \\
\hline & Heterozygous & 18 & 16,8 & 10 & 8,9 & 28 & 12,8 & & \\
\hline Mutation ly & Homozygous & 15 & 14,0 & 13 & 11,6 & 28 & 12,8 & 3,091 & ו \\
\hline
\end{tabular}

ф: Chi-square analysis 
Table 3. The demographic and clinical characteristics of the VTE patient subgroups

\begin{tabular}{|c|c|c|c|c|}
\hline Parameters & DVT (n:58), n (\%) & IAVT, n (n:5) (\%) & PE (n:29), n ( \%) & CVT (n:33), n ( \%) \\
\hline $\begin{array}{l}\text { Age, (year) } \\
\text { (mean) }\end{array}$ & $17-76,(40.1)$ & $31-63,(53.4)$ & $17-75,(42.3)$ & $16-59,(36)$ \\
\hline $\begin{array}{l}\text { Gender }(\mathrm{F} / \mathrm{M}) \\
\left(\mathrm{p}^{\phi}\right)\end{array}$ & $\begin{array}{c}3.1, \\
(\mathrm{p}=0.004)\end{array}$ & $\begin{array}{c}0.7 \\
(p>0.05)\end{array}$ & $\begin{array}{c}1.9 \\
(p>0.05)\end{array}$ & $\begin{array}{c}0.8 \\
(\mathrm{p}=0.009)\end{array}$ \\
\hline $\begin{array}{l}\text { Most Common } \\
\text { Mutation, } \mathrm{n}(\%)\end{array}$ & $\begin{array}{c}\text { ACE, } \\
50(86.2 \%)\end{array}$ & $\begin{array}{c}\text { PAI-4G\&5G, } \\
6(100 \%)\end{array}$ & $\begin{array}{c}\text { PAI-4G\&5G, } \\
26(89.6 \%)\end{array}$ & $\begin{array}{c}\text { ACE, } \\
25(75.8 \%)\end{array}$ \\
\hline $\begin{array}{l}\text { Statistically } \\
\text { Significant } \\
\text { Mutation, } \\
\mathrm{n}(\%) \\
\left(\mathrm{p}^{\phi}\right)\end{array}$ & $\begin{array}{c}\text { FactorVG1691A } \\
20,(76,9 \%) \\
(p=0.008) \\
\text { MTHFRA1298C } \\
39,(62.9 \%) \\
(p=0.034)\end{array}$ & - & - & $\begin{array}{c}\text { FactorVG1691A } \\
\quad 22,29.7 \% \\
(p=0.049)\end{array}$ \\
\hline
\end{tabular}

VTE= Venous thromboembolism, DVT=Deep vein thrombosis, IAVT=Intraabdominal vein thrombosis $\mathrm{PE}=$ Pulmonary embolism, $\mathrm{CVT}=$ Cerebral vein thrombosis

$\phi$ : Chi-square analysis

$(6,18)$. In clinic, DVT is seen in $10 \%$ of the PE patients (18). PE develops in approximately 20\% of untreated DVTs and progresses fatally with a rate of $10-20 \%(9,19)$. In our study, DVT was detected in $54.2 \%$, and PE in $27.1 \%$ of the VTD patients. DVT was statistically significantly more common in female patients. In our study, the statistically significant defect was Factor V G1691A (Leiden) mutation in patients similar to the literature.

Factor V G1691A mutation is the most common cause of hereditary thrombophilia $(8,10)$. The incidence of this mutation is between $2-14 \%$ in the population (20). In our study, the rate of Factor $\mathrm{V}$ heterozygous Leiden mutation was statistically significant higher in the VTD patients. Moreover, factor V G1691A mutation was statistically significantly higher in the DVT and CVT patients.

Factor V H1299R mutation was seen in $2.3 \%$ of the population; while it was found as $24.3 \%$ in our study (20). Prothrombin G20210A mutation was seen at $6 \%$ in VTD; while it was found as $7.5 \%$ in our study $(2,10)$.

If the enzyme activity decreases as a result of the mutation in the MTHFR enzyme gene, the plasma homocysteine level increases and it is a risk factor for venous thrombosis $(2,9,20)$. Sixty percent of the white race carry the MTHFR allele, of which $1.4-15 \%$ are TT (homozygous) (10). In our study, MTHFR C677T TT (homozygous) ratio was $10.3 \%$ in VTD patients.

MTHFRA $1298 \mathrm{C}$ mutation has been detected as $4.8 \%$ in the VTD patients, and it has been reported to increase the VTD risk (20). In our study, the rate of MTHFRA 1298 CC homozygous mutation was $14 \%$ in VTD patients. In addition, MTHFRA 1298 C mutation was statistically significant in the DVT patients.

In the Caucasian population, Factor XIII V34L polymorphism has been reported to be heterozygous by $32-43 \%$ and homozygous by $4-$ $10 \%(21,22)$. In our study, the rate of Factor XIII V34L mutation was $30.8 \%$ in VTD patients, of which $1.9 \%$ were LL homozygous.

$\beta$-Fibrinogen-455 G/A $\beta$ Hae III) gene polymorphism occurs in $8-10 \%$ of the normal population $(13,20)$. In our study, the rate of $\beta$ Fibrinogen -455G/A mutation was $57.9 \%$ in VTD patients, of which $10.3 \%$ were of AA homozygous genotype.

4G/5G genotype of PAI-4G\&5G gene polymorphism, which increases the VTD risk, occurs in $48 \%$ of healthy individuals $(10,20)$. In our study, the rate of PAI-4G\&5G gene mutation was $73.8 \%$ in the patients, of which $19.6 \%$ were of 4G/4G homozygous genotype.

In the white race, the distribution of ACE gene polymorphism, which increases the VTD risk, is in the form of II genotype by $25 \%$, ID genotype by $50 \%$, and DD genotype by $25 \%$. Angiotensin II forms are more common in the DD genotype $(10,20,21)$. In our study, ACE gene mutation was detected as $82,2 \%$ in the VTD patients. Of these, $39.3 \%$ had D/D homozygous genotype. ACE gene mutation was statistically significantly higher in the female patients.

In East Asia, the rate of heterozygous HPA-1 $(a / b)$ is $5-22 \%$, and the rate of homozygous HPA-

East J Med Volume:25, Number:1, January-March/2020 
1 (b/b) is $0-0.5 \%(10,24)$. In our study, the rate of heterozygous HPA-1 (a/b) was $28 \%$ and the rate of homozygous HPA-1 (b/b) was $2.8 \%$ in the VTD patients.

In Europe, of the population, 95\% carries at least one apoE-e3 allele, $27 \%$ carries at least one apoEe4 allele, and $16 \%$ carries at least one apoE-e2 allele (25). In our study, the of Apo E gene mutation was $30.3 \%$ in the VTD patients, of which 14\% consisted of homozygous ApoE mutation. However, in our study, Apo E mutation rates were not statistically significant.

VTD frequently recurs (1). The recurrence rate of VTD is $12.9 \%$ within one year and $30.4 \%$ within ten years $(2,3)$. The risk of recurrence is highest within the first $6-12$ months $(3,6)$. As long as the anticoagulant therapy is continued, the recurrence of VTD is prevented by $95 \%$. However, VTD recurs in $20-50 \%$ of the patients within the first 10 years following the discontinuation of the treatment (6).

In those with two or more combined thrombophilic defects, VTD occurs at a younger age and the risk of recurrent VTD is higher (8). Life-long anticoagulant therapy is recommended for those with combined thrombophilic anomalies and to the high-risk group of recurrent VTD $(8,9)$. A family screening may be performed to confirm thrombophilic disorder in a patient presenting with VTD (9).

The common venous thromboembolic disease in general population causes significant complications. Therefore, the etiology should be well known and appropriate measures should be taken. Nowadays, many mutations have been found to cause venous thromboembolic disease. The cause of hereditary thrombophilia may not always be antithrombin III, protein $\mathrm{C}$ or protein $\mathrm{S}$ deficiency. In this case, genetic mutations that are rarely seen in the diagnosis and treatment planning of VTD should be considered.

\section{References}

1. Ho WK, Hankey GJ, Lee CH, Eikelboom JW. Venous thromboembolism: diagnosis and management of deep venous thrombosis. Med J Aust 2005; 182: 476-481.

2. Segal JB, Eng J, Tamariz LJ, Bass EB. Review of the Evidence on Diagnosis of Deep Venous Thrombosis and Pulmonary Embolism. Ann Fam Med 2007; 5: 63-73.

3. Heit JA, Spencer FA, White RH. The epidemiology of venous thromboembolism. J Thromb Thrombolysis 2016; 41: 3-14.
4. Bezgin T, Kaymaz C, Akbal Ö, Y1lmaz F, Tokgöz HC, Özdemir N. Thrombophilic Gene Mutations in Relation to Different Manifestations of Venous Thromboembolism: A Single Tertiary Center Study. Clin Appl Thromb Hemost 2018; 24: 100106.

5. Walker ID, Greaves M, Preston FE. Haemostasis and Thrombosis Task Force; British Committee for Standards in Haematology: Investigation and management of heritable thrombophilia. $\mathrm{Br} \mathrm{J}$ Haematol 2001; 114: 512-528.

6. Heit JA. Epidemiology of venous thromboembolism. Nat Rev Cardiol 2015; 12: 464-474.

7. Klaassen IL, van Ommen $\mathrm{CH}$, Middeldorp S. Manifestations and clinical impact of pediatric inherited thrombophilia. Blood 2015; 125: 10731077.

8. Esmon CT. Basic Mechanisms and Pathogenesis of Venous Thrombosis. Blood Rev 2009; 23: 225229.

9. Stone J, Hangge P, Albadawi $\mathrm{H}$, et al. Deep vein thrombosis: pathogenesis, diagnosis, and medical management. Cardiovasc Diagn Ther 2017; 7: 276-284.

10. Khan S, Dickerman JD. Hereditary thrombophilia. Thromb J 2006; 4: 15.

11. Bargahi N, Ghorbian S, Zonouzi AA, Zonouzi AP. Genetic susceptibility to deep venous thromboembolism: the roles of inherited thrombophilia polymorphisms. Blood Coagul Fibrinolysis 2016; 27: 308-312.

12. Colucci G, Tsakiris DA. Thrombophilia Screening: Universal, Selected, or Neither? Clin Appl Thromb Hemost 2017; 23: 893-899.

13. Yilmaz S, Gunaydin S. Inherited risk factors in low-risk venous thromboembolism in patients under 45 years. Interact Cardiovasc Thorac Surg 2015; 20: 21-23.

14. Barsoum MK, Heit JA, Ashrani AA, Leibson CL, Petterson TM, Bailey KR. Is progestin an independent risk factor for incident venous thromboembolism? A population-based casecontrol study. Thromb Res 2010; 126: 373-378.

15. White RH, Zhou H, Romano PS. Incidence of symptomatic venous thromboembolism after different elective or urgent surgical procedures. Thromb Haemost 2003; 90: 446-455.

16. Chew HK, Wun T, Harvey D, Zhou H, White $\mathrm{RH}$. Incidence of venous thromboembolism and its effect on survival among patients with common cancers. Arch Intern Med 2006; 166: 458-464.

17. James AH. Venous thromboembolism in pregnancy. Arterioscler Thromb Vasc Biol 2009; 29: 326-331.

18. Heit JA, Mohr DN, Silverstein MD, Petterson TM, O'Fallon WM, Melton LJ. Predictors of recurrence after deep vein thrombosis and 
pulmonary embolism: a population-based cohort study. Arch Intern Med 2000; 160: 761-768.

19. Huang W, Goldberg RJ, Anderson FA, Kiefe CI, Spencer FA. Secular trends in occurrence of acute venous thromboembolism: the Worcester VTE study (1985-2009). Am J Med 2014; 127: 829-839.

20. Kreidy R. Influence of acquired and genetic risk factors on the prevention, management, and treatment of thromboembolic disease. Int J Vasc Med 2014; 2014: 859726.

21. Akar N, Akar E, Misirlioğlu M, Avcu F, Yalçin A, Cin S. Search for genetic factors favoring thrombosis in Turkish population. Thrombosis research 1998; 92: 79-82.

22. Shemirani AH, Haramura G, Bagoly Z, Muszbek L. The combined effect of fibrin formation and factor XIII A subunit Val34Leu polymorphism on the activation of factor XIII in whole plasma. Biochimica et Biophysica Acta 2006; 1764: 1420 1423.

23. Renner W, Cichocki L, Forjanics A, Köppel H, Gasser R, Pilger E. G-455A polymorphism of the fibrinogen beta gene and deep vein thrombosis. Eur J Clin Invest 2002; 32: 755-758.

24. Tan J-Y, Lian L-H, Nadarajan VS. Genetic polymorphisms of human platelet antigens-1 to 6 , and -15 in the Malaysian population. Blood Transfus 2012; 10: 368-376.

25. Aboud O, Mrak RE, Boop F, Griffin ST. Apolipoprotein epsilon 3 alleles are associated with indicators of neuronal resilience. BMC Med 2012; 10: 35. 